\title{
INFLUENCE OF ALTERNATING TEMPERATURE LEVELS ON THE WEAR BEHAVIOR OF RADIAL LIP SEALS: TEST RIG DESIGN AND WEAR ANALYSIS
}

\author{
UDC: $62-762.64$
}

Original scientific paper

\author{
Lukas Merkle $^{1^{*}}$, Matthias Baumann ${ }^{1}$, Frank Bauer ${ }^{1}$ \\ ${ }^{1}$ University of Stuttgart - Institute of Machine Components, Stuttgart, Germany
}

\begin{abstract}
:
Radial lip seals are a common seal type for various industrial applications. In retarder breaking systems for commercial vehicles, radial lip seals are exposed to very fast changing oil sump temperatures. Due to increasing demands, the elastomer seals are increasingly failing premature in such applications. It is assumed that this is caused in particular by the very high temperature gradients, that result from the fact that a lot of braking power is dissipated within a short time. This is the case, for example, when braking while driving downhill with heavy loads. Since the temperature gradient is of minor importance in many applications, there are no publications regarding the specific influence of high temperature gradients on the function of radial shaft seals. Therefore, a test rig with advanced heating and cooling capacities is developed.

A comprehensive test series is carried out, with the main focus on the influence of high temperature gradients on the wear behavior of the seals. Test results show, that different temperature levels lead to a significant change of the wear behavior. Additionally, fast changing temperatures are adding additional tribological stress to the sealing system.
\end{abstract}

ARTICLE HISTORY Received: 05.08.2021. Accepted: 10.09.2021. Available: 30.09.2021.

\section{INTRODUCTION}

A frequent task in mechanical engineering is the sealing of rotating components (shafts) against a stationary component (housing). Due to the good static leak tightness and the active back pumping mechanism in dynamic operation, elastomeric radial lip seals are used to seal shaft interfaces in many industrial applications. Radial lip seals are used in all sectors of the automotive industry, in mechanical and plant engineering, and in many other areas. There is a wide variety of requirements in terms of shaft diameters, speeds and the fluid to be sealed. Therefore, radial lip seals are available at the market in different sizes and designs, as well as in different materials. Typical materials are FKM (fluoro rubber) and NBR (nitrile rubber). In addition to individual, application related designs, DIN 3760/ $3761[1,2]$ specifies a number of standards. Together with the fluid to be sealed and the sealing counterface (shaft), the elastomeric sealing ring forms a tribological sealing system. A typical sealing system is shown in Fig. 1.

In the automotive sector, radial lip seals are installed in all parts of the drive train. In many commercial vehicles, the wear-free retarder brake is also part of it. Without applying the vehicle breaks, no energy is dissipated in the retarder systems. The retarder shaft rotates continuously, while the oil temperatures are relatively low. When braking while driving downhill with heavy loads, the retarder system has to dissipate the kinetic energy of the decelerating vehicle. The oil temperature rises sharply without a particular change of the sliding speed. The radial lip seals are then exposed to very fast changing oil sump temperatures. Elastomer radial lip seals are increasingly failing in such applications with very high temperature gradients. This leads to the research question: what 
are the influences of fast alternating temperature levels on function and lifetime of radial lip seals? The aim of the presented investigation is to analyze the tribological conditions in the sealing gap and the wear behavior of the sealing edge.

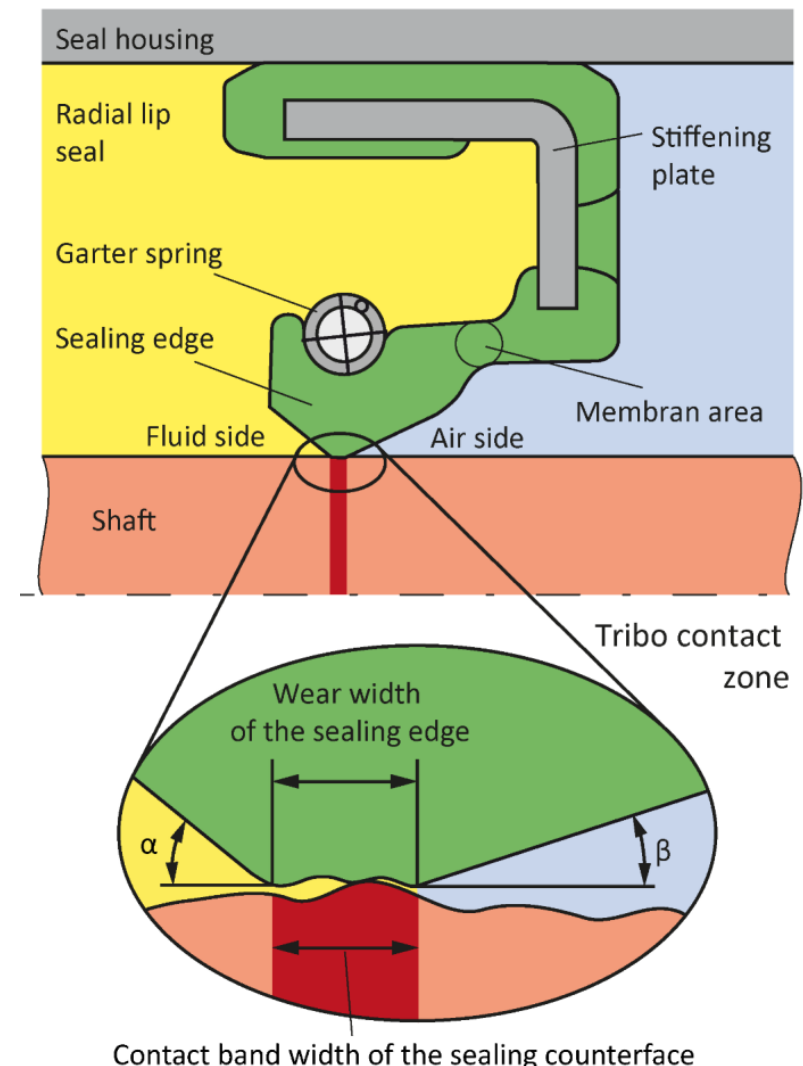

Fig. 1. Sealing system radial lip seal with shaft and fluid. Radial lip seal according to DIN 3760 form A [1] and detail view of the tribo contact zone (bottom) $[3,4]$

In research and industry, there are many years of experience in the use of radial lip seals. Nevertheless, damage and wear formation cannot yet be predicted with certainty due to the manifold failure mechanisms that can occur. The design of modern sealing systems is based a lot on empirical values and is therefore always associated with a certain degree of uncertainty. To ensure troublefree operation and to avoid unplanned downtimes, it must be possible to estimate the behavior of the system in advance, especially when introducing new sealing systems. Analytical calculation methods and simulative approaches, as are common for other machine elements, quickly reach their limits in the field of sealing technology. Functional reliability still has to be verified by tests on test rigs or in field tests.

Some standardized test methods have been established in industrial applications for testing the function of radial lip seals. On the one hand,
DIN 3761 part 10 and 11 [5,6] contains some specifications, but on the other hand, various companies have developed their own specific test cycles [7]. The "Flender test" for industrial gear unit applications is for example a two-stage test run with a standstill phase and a phase of constant circumferential speed of $5.5 \mathrm{~m} / \mathrm{s}$ with a running distance of 16,625 km [8]. In comparison, the "SEW test" is designed to be much more highly dynamic, with fast changes in speed and direction of rotation at up to $12 \mathrm{~m} / \mathrm{s}$ circumferential speed [9]. The test cycles all have in common that different velocities are considered, but the temperature is always kept constant for long durations. The "Flender test" is carried out with temperatures between $\theta=80 \ldots 110^{\circ} \mathrm{C}$ (depending on the oil type, and elastomeric material) during the running sequence and a passive cool down during standstill. The "SEW test" is carried out at always constant temperatures of $\theta=70 \ldots 110^{\circ} \mathrm{C}$ (also depending on the oil type, and elastomeric material).

In the most research work, constant or selfregulated oil sump temperatures are used. For example, in $[10,11]$ "transient operating conditions" and "variable temperature" are investigated, but always with constant oil sump temperature during the duration of a test run. In [12] the test runs are carried out with constant oil sump temperatures of $80^{\circ} \mathrm{C}$ or $110^{\circ} \mathrm{C}$. High temperature gradients and temperature collectives have not been tested so far. To date, there is no research findings or data basis to assess the damage potential of quickly changing temperatures.

\section{MATERIAL AND METHODS}

The following section describes the test rig design, the methods of wear measurement and the experimental approach to investigate alternating temperature conditions. The test rig used is especially designed for this purpose and is therefore described in detail.

\subsection{Test rig design}

To test fast-changing temperatures, an additional test chamber is designed [13]. It is to be mounted modularly on the existing test rig, used at the institute, Fig. 2 . The design and functionality of the additional test chamber is described in this chapter. The aim of the design is to build a test chamber that allows temperature changes between 
$40^{\circ} \mathrm{C}$ and $120^{\circ} \mathrm{C}$ as fast as possible. To achieve high temperature gradients the following design guidelines are applied:

- Low thermal inertia thanks to reduced oil volume and mass of the test chamber

- A high heating capacity

- A high cooling capacity.

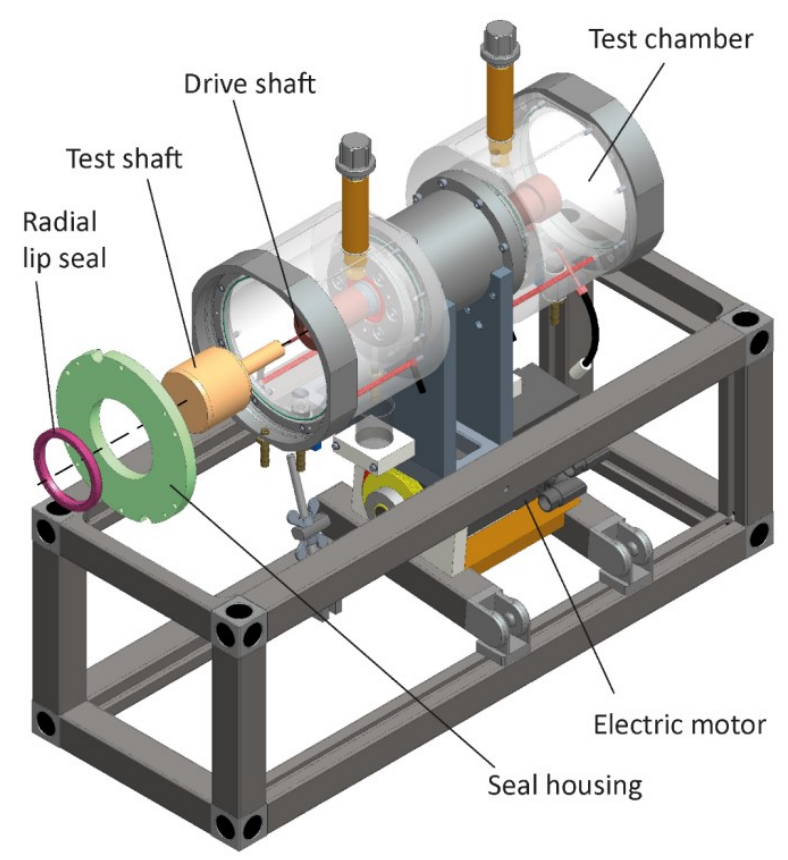

Fig. 2. Modular test rig for endurance test runs

In the standard configuration of the endurance test rig, the radial lip seal is mounted in an adaptable housing. The electric motor drives the central shaft in the middle of two identical test chambers. The test chambers are filled with the oil to test and the test shafts are mounted to the drive shaft. The two test chambers allow to test two individual sealing systems on one test rig module. The test rig itself has a modular design and is built of multiple modules. The test runs can be therefore carried out simultaneously on several modules in parallel. The test chamber can be heated with heating cartridges, or cooled with cooling water supply. However, the heating and cooling capacity in the standard test chamber is not sufficient to achieve the required temperature gradients. The additional test chamber is therefore mounted instead of the standard seal housing.

The assembly of the additional test chamber for dynamic temperature changes is shown in Fig. 3. The test chamber is designed for an average fluid volume of 0.5 liters for a filling level up to the center of the shaft. According to DIN 3761 part 10 [5] the recommended oil volume for testing radial lip seals with an outer diameter up to $\varnothing 140 \mathrm{~mm}$ is 0.75 liters. The outer diameter of the tested sealing system (see chapter 2.3 ) is $\varnothing 100 \mathrm{~mm}$. Therefore, the reduced fluid volume will still be sufficient.

Six high-performance electric heating cartridges are used to heat the chamber. The wall thickness of the additional test chamber is designed for heating cartridges with a diameter of $6.5 \mathrm{~mm}$. The maximum length of the chamber is $120 \mathrm{~mm}$.

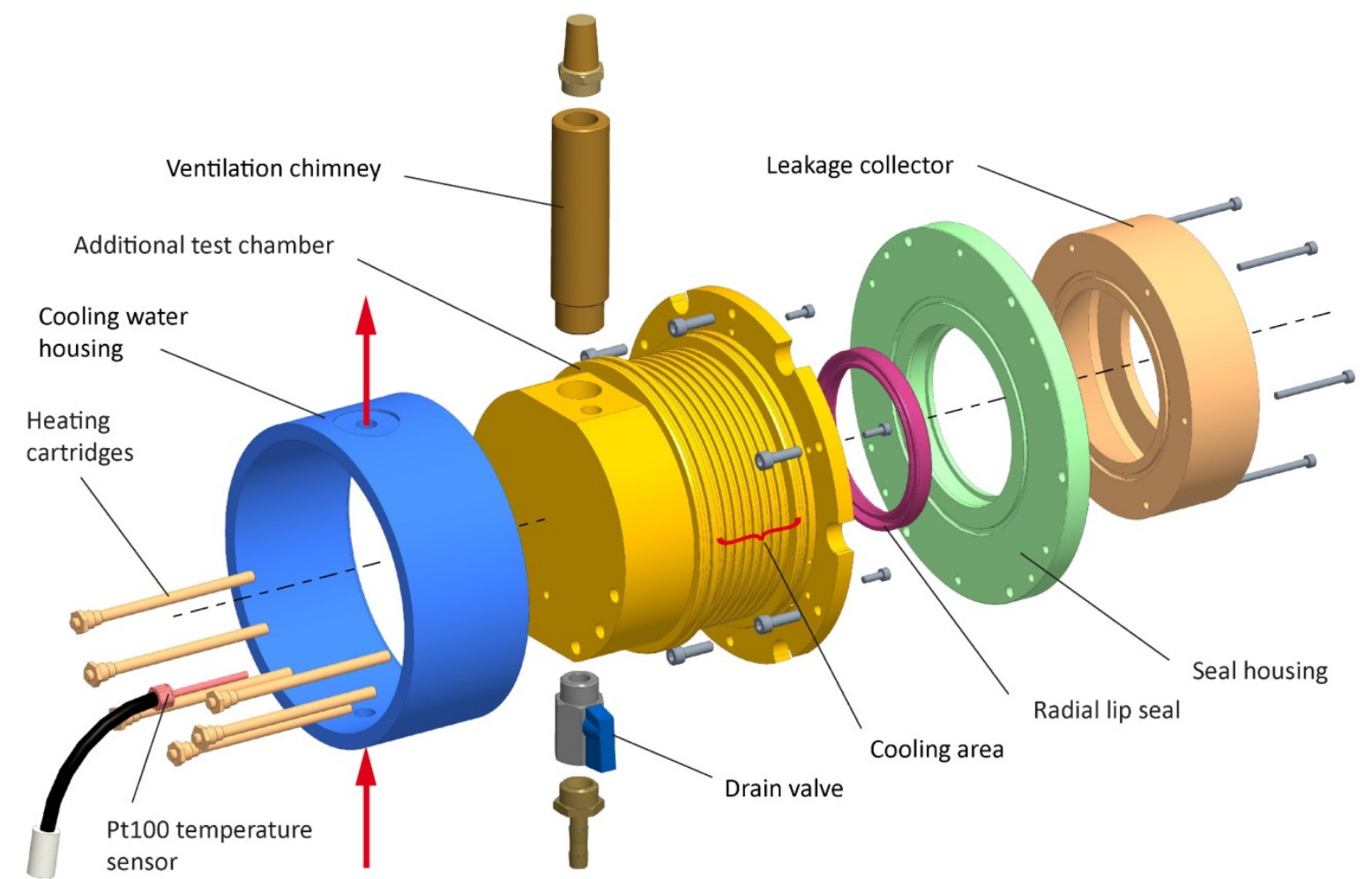

Fig. 3. Components of the additional test chamber in exploded view 
The power of the heating cartridges is chosen as high as possible to maximize the heat flow and thus minimize the heating time. The selected heating cartridges have a nominal power $p_{\text {nom }}=350 \mathrm{~W} \pm 10 \%$ at a length of $100 \mathrm{~mm}$. This means, there is a cumulated heating power of $p \approx 2 \mathrm{~kW}$ per test chamber.

$$
\begin{gathered}
p=6 \cdot 350 \mathrm{~W} \pm 10 \%=2100 \mathrm{~W} \pm 10 \% \\
=1890 \mathrm{~W} \ldots 2310 \mathrm{~W}
\end{gathered}
$$

The heating cartridges are mounted in the aluminum test chamber housing. They have no direct contact to the fluid in the test chamber. The heat is transferred by the housing to the fluid. The heating is uniform and the fluid cannot overheat locally, which prevents unintended oil carbonization.

To cool the additional test chamber, the cooling water can flow around a large part of the outer surface. To improve heat transfer, the housing is provided with cooling fins. The cold cooling water is introduced at the bottom of the chamber through a control valve, and the hot cooling water is discharged at the top. The valves, as well as the heating cartridges, are directly controlled by the test rig control system. The test chamber can be operated with any external cooling or heating circuit. In the present case, a connection is made to the existing in-house cooling water network. The cooling water is provided with an average cooling water temperature of $18^{\circ} \mathrm{C}$ and a supply and return pressure between 2 and 4 bar. Due to the overpressure in the cooling system, the cooling water can be heated up to $120^{\circ} \mathrm{C}$ without any problems. The temperatures in the oil sump are measured and regulated with a commercially available Pt-100 temperature sensor. The Pt-100 sensor is placed axial in the additional test chamber, in the center of the oil sump. The oil sump temperature is controlled individually for each test chamber by the test rig control system by switching on the heating cartridges or opening the cooling water valves. The control is done with a simple twopoint controller with a threshold value of $\pm 2 \mathrm{~K}$.

The test chamber is assembled in two steps. In the first step, the test shaft is installed in the test rig in the regular way. The radial lip seal is mounted into the seal housing first and then the seal housing with the seal is mounted on the shaft. In the second step, the additional test chamber is mounted on the seal housing and filled with fluid. The cooling water housing can remain on the test chamber and does not have to be removed. The cartridge heaters and the Pt-100 temperature sensor can be disconnected by plug-in connections. The cooling water connections also have self-sealing quick disconnect couplings so that the connections can be disconnected without a loss of cooling water.

Fig. 4 shows a cross section of the test rig with mounted additional test chamber (left) and in the standard configuration (right).

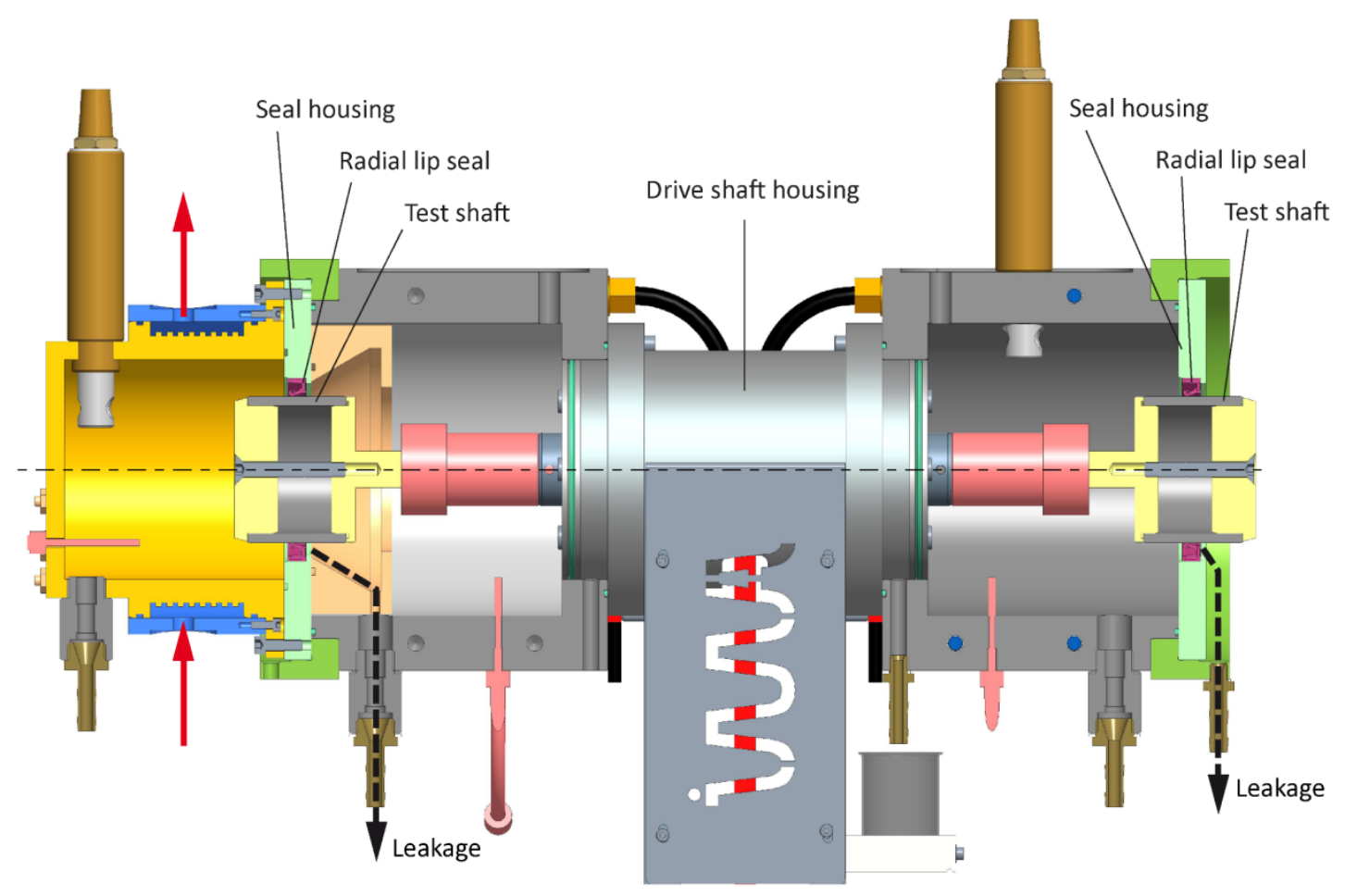

Fig. 4. Additional test chamber (left) and standard configuration (right) 
The reduced fluid volume of the additional test chamber is clearly visible. The disadvantage of the additional test chamber compared to the standard configuration is the lack of direct accessibility to the sealing contact. Any leakage must therefore be diverted via the leakage collector through the standard test chamber.

Fig. 5 shows the test chambers in use. On the left side, two test chambers in standard configuration are in operation. On the right side, two additional test chambers are mounted. The additional test chambers can be mounted modularly on the test rig without any further modifications. The cooling water is supplied from above by a central cooling water distributor. The heating cartridges are connected via a small additional control cabinet.

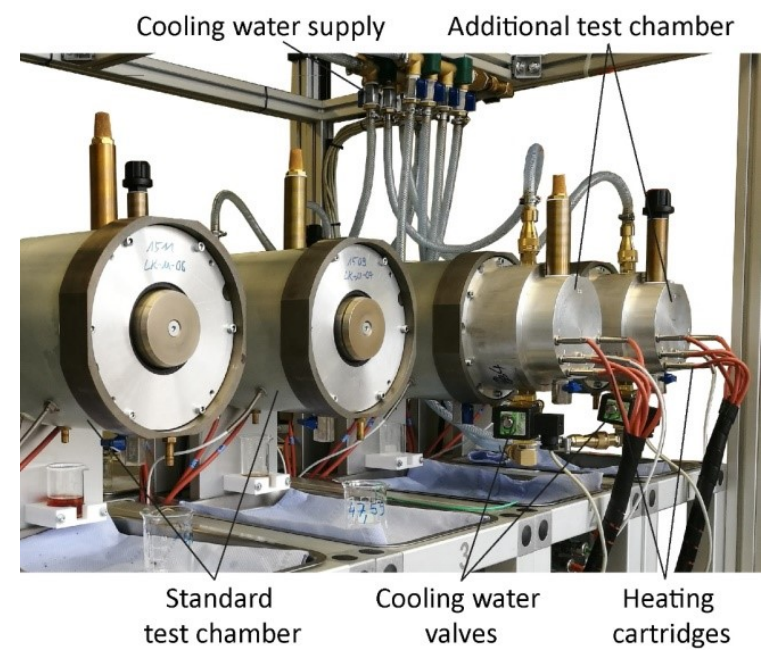

Fig. 5. Additional test chambers on test rig

\subsection{Wear evaluation of the sealing edge}

In order to analyze the effects of different temperature conditions, a series of test runs is carried out with the test rig as described. The aim is to investigate the occurrence of wear under different operating conditions. In particular, the wear of the sealing edge is recorded. Different temperature levels, as well as different transient temperature conditions, lead to different degrees of wear of the sealing edge. Fig. 6 shows an example of two worn sealing edges.

The greater the wear rate at the sealing edge, the more damaging the respective operating condition is for the sealing system. Extensive wear can lead to leakage and thus to failure of the sealing system [3]. The wear can be uniform (i.e. symmetrical). Then, all areas of the sealing edge around the circumference of the sealing ring are worn to a similar extent. The wear can also be uneven (i.e. asymmetrical). Different circumferential positions on the sealing edge have significantly different amount of wear.

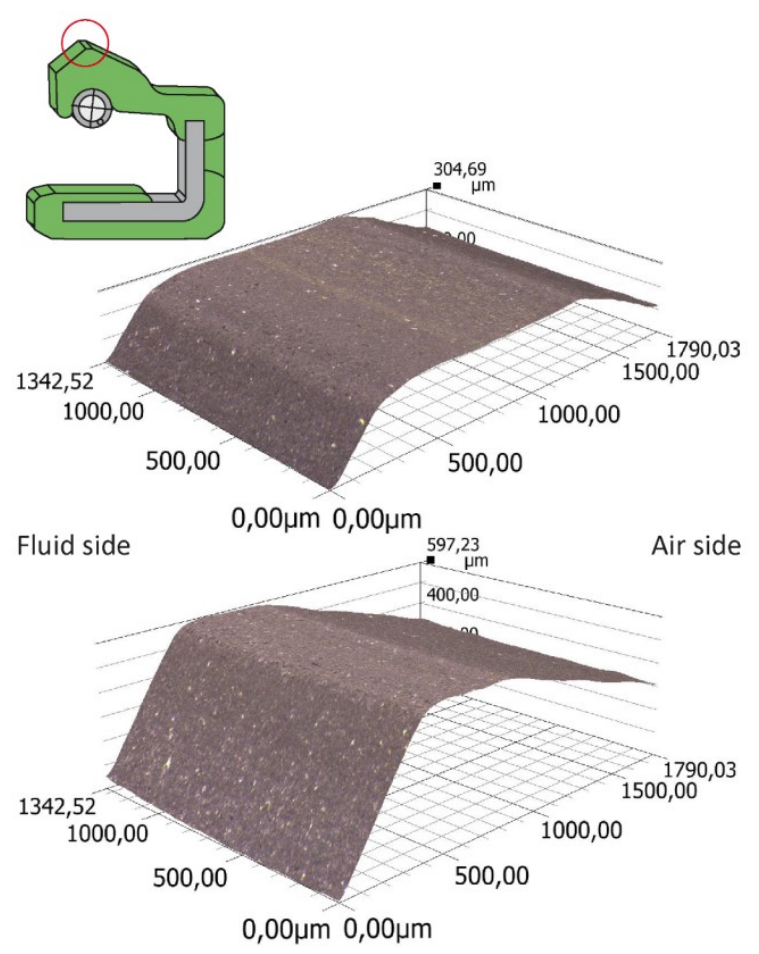

Fig. 6. Wear formation of the sealing edge of an elastomeric radial lip seal: sealing edge with large wear width (top) and sealing edge with medium wear width (bottom)

The common characteristic value for wear at the sealing edge of a radial lip seal is the wear (band) width $[3,8,14]$. It can be measured directly and determines the contact band width and thus the sealing function [15]. The tribological function of the radial lip seal is directly dependent on the pressure and specifically on the pressure distribution in the sealing contact. This is highly dependent on the contact band width of the sealing edge. The wear cross-section or the wear volume gives no direct indication of the pressure distribution. Both are therefore useless for a tribological functional description of radial lip seals [3]. Particularly in the case of strongly asymmetrical wear, the wear volume is not a suitable unit of measurement.

The wear width measurement on the radial lip seal can be carried out in various ways. The trivial way is to measure the wear width on images, taken with a digital microscope (cf. Fig. 6). These images are normally taken anyway to carry out an optical analysis of the state of the sealing edge. The wear width can be measured on these images if the worn surface is aligned horizontally. Otherwise, an angular error will falsify the measurement result. In this way, the wear width of the sealing edge can be determined at a small amount of different positions. 
For a complete acquisition of the tribological conditions at the sealing edge, an almost continuous recording of the wear width is necessary. This would require a large number of images to be measured by hand. However, this would be very time-consuming and error-prone. Therefore, a special developed measuring system is used for this task. The IMA-Sealscannner ${ }^{\circledR}[16]$ can automatically measure and evaluate the sealing edge geometry of a radial lip seal. Fig. 7 shows the measuring principle.

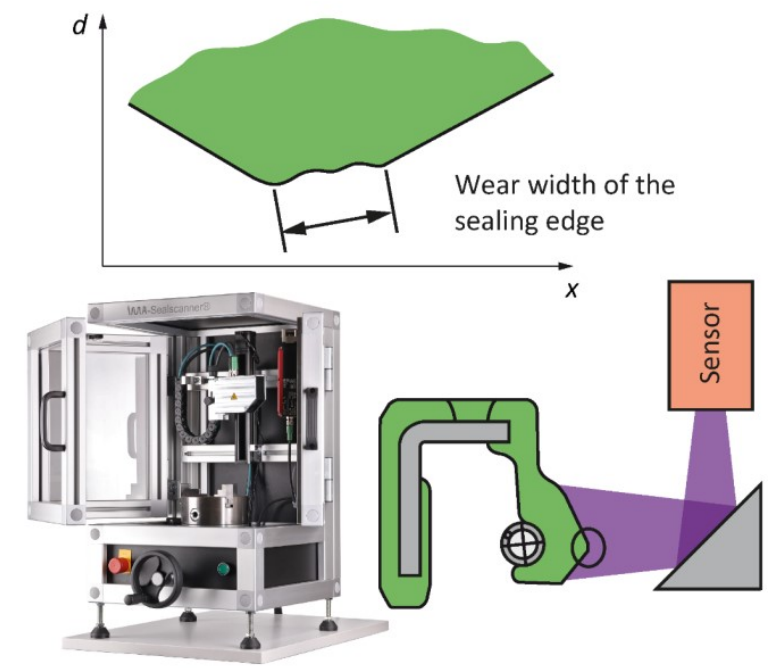

Fig. 7. Fully automatic wear width measurement with laser line triangulation

With laser line triangulation, individual profiles of the sealing edge geometry are recorded. With its laser sensor, each profile is mapped with 1024 measuring points at a distance of $16 \mu \mathrm{m}$. By means of a rotational feed 10,000 profiles are recorded on the circumference of the radial lip seal. This means that every $0.036^{\circ}$ the wear width is recorded. The wear width is automatically evaluated for each profile. This method considerably improves the wear width measurement. The number of measuring points is increased and the time required can be significantly reduced compared to manual measurements. The measurement is fully automatic and therefore user-independent. Due to the high-resolution recording of the wear width distribution, this method allows better conclusions about the condition of the tribological system radial lip seal. Asymmetric wear, which is often found for tribological unfavorably operated sealing systems, becomes evident in this way.

All radial lip seals are evaluated in this way. The measurement results are presented in the form of bar charts. They show the minimum and the maximum measured wear width for each radial lip seal. The frequency distribution of the measured wear widths between the minimum and maximum values are indicated using different grey values.

\subsection{Materials and experimental approach}

To evaluate the wear formation at the sealing edge under alternating temperature conditions, various test runs are carried out. To reach a maximum comparability, most test conditions are hold constant. The examined sealing system has a diameter to be sealed of $80 \mathrm{~mm}$. Such sealing systems are not only representative for the mentioned retarder example, but also for various industrial and automotive gearbox designs and other applications.

The radial lip seals used are standard products from the manufacturer Freudenberg Sealing Technology. They are used in various other research projects throughout the research association FVA (Forschungsvereinigung Antriebstechnik e.V.) and current research work (e.g. $[10,17,18])$. They offer therefore the best comparability of the test results. The seal type used is BAUM5X7 with the designation 80-100-10 (dimensions: inside diameter $80 \mathrm{~mm}$, outside diameter $100 \mathrm{~mm}$, thickness $10 \mathrm{~mm}$ ). The material used for the sealing rings is 75FKM585. This fluorelastomer is chemically and thermally stable, which means that interaction with the fluid (oil) and the environment (oxygen) can be excluded. The test shaft consists of needle roller bearing inner rings (IR) which are mounted on a shaft adapter. Needle roller bearing inner rings can be obtained from various bearing manufacturers. Inner rings of sizes $70 \times 80 \times 54$ and $70 \times 80 \times 25$ with an outside diameter of $80 \mathrm{~mm}$ and lengths of 54 and $25 \mathrm{~mm}$ are used. The sealing counterface on the shaft surface are ground lead free with rotating grinding wheel. All shafts are measured in detail before the start of the test and are evaluated with regard to their suitability with state of the art evaluation methods (cf. $[17,19])$. The scatter of the test results due to different shaft properties is thus reduced to a minimum. Runout deviation of the shaft and coaxiality of shaft and sealing ring are measured significantly below the manufacturer's specifications [20]. As fluid, the mineral FVA 3 reference oil [21] is used. The viscosity corresponds to an SAE 80 oil and is therefore representative for a typical transmission oil. The reference oils always have an identical chemical composition and are not additivated. The materials are summarized in Table 1. 
Table 1. Overview of materials used for the test runs.

\begin{tabular}{|l|l|}
\hline $\begin{array}{l}\text { Radial } \\
\text { lip seal }\end{array}$ & $\begin{array}{l}\text { Type BAUM5X7 } \\
\text { Dimension } 80-100-10 \mathrm{~mm} \\
\text { Material FKM 585 }\end{array}$ \\
\hline Shaft & $\begin{array}{l}\text { Material 100Cr6 } \\
\text { Plunge ground leadfree with a rotating } \\
\text { grinding wheel } \\
\text { Measured and evaluated }\end{array}$ \\
\hline Fluid & $\begin{array}{l}\text { FVA reference oil no. 3 } \\
\text { Mineral oil without additives } \\
\text { Viscosity corresponds to SAE 80 }\end{array}$ \\
\hline
\end{tabular}

Using this sealing system, this paper will take a closer look to the wear effect at the sealing edge. The main focus is to detect harmful operating conditions, and to reveal the tribological correlation between dynamic temperature changes and the wear effects. The aim is to be able to estimate the wear behavior and predict the live time of a sealing system under known operating conditions. The test runs are carried out with two different circumferential velocities. The temperature levels are varied according to the test plan in Table 2 .

Table 2. Test runs carried out with a circumferential velocity of $v_{1}=4.2 \mathrm{~m} / \mathrm{s}$ and $v_{2}=10 \mathrm{~m} / \mathrm{s}$

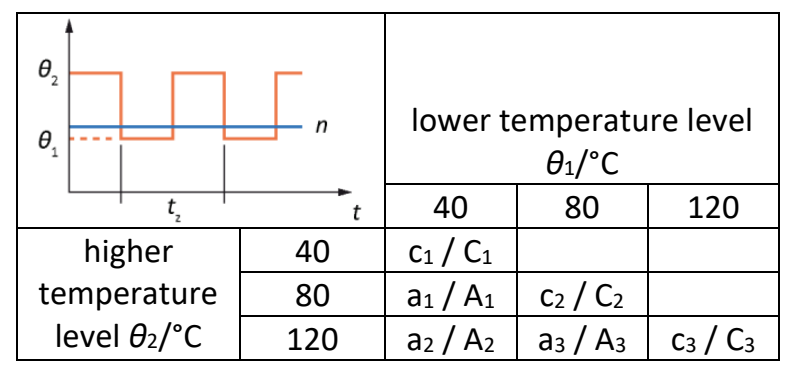

$\mathrm{C}_{\mathrm{x} . . .}$ constant temp. at lower velocity $(4.2 \mathrm{~m} / \mathrm{s})$

$C_{x} . .$. constant temp. at higher velocity $(10 \mathrm{~m} / \mathrm{s})$

$a_{x} \ldots$ alternating temp. at lower velocity $(4.2 \mathrm{~m} / \mathrm{s})$

$A_{x \ldots}$ alternating temp. at higher velocity $(10 \mathrm{~m} / \mathrm{s})$

The test runs are carried out with 3 temperature levels $\theta=40^{\circ} \mathrm{C} ; 80^{\circ} \mathrm{C} ; 120^{\circ} \mathrm{C} . \theta=40^{\circ} \mathrm{C}$ is set as the lower temperature. Tempering to lower temperatures would be possible, but would require more effort. Due to the friction-induced selfheating, an equilibrium temperature of approx. $35^{\circ} \mathrm{C}$ is established by counter-cooling with the available in-house cooling water supply. $\theta=40{ }^{\circ} \mathrm{C}$ can thus always be safely reached. With this oil sump temperature, the usual operating conditions for radial lip seals are well mapped. At very low temperatures, the elastomeric material show fundamentally different material properties [22]. Therefore, low temperature applications are being considered in other projects. At $\theta=120^{\circ} \mathrm{C}$, the operating limit of the FKM material of the radial lip seal is reached. According to the manufacturer's specifications [20] the maximum temperature in continuous operation is $150^{\circ} \mathrm{C}$. In the present case, in combination with a circumferential velocity $v_{2}=10 \mathrm{~m} / \mathrm{s}, \theta=120^{\circ} \mathrm{C}$ is the highest reachable temperature without risking major thermal damage. All test runs are carried out with a period duration $t_{z}=2 \mathrm{~h}$ (see Table 2 , right).

First, a reference test with constant temperature is performed for each temperature level (test runs $\mathrm{C}_{1} / \mathrm{C}_{1}$ to $\left.\mathrm{C}_{3} / \mathrm{C}_{3}\right)$. Then the temperature levels are combined according to Table 2 . In industrial applications, alternating temperatures are often, but not exclusively, related to changing velocities. While changing velocities are often studied (e.g. $[5,7,10])$, the influence of changing temperatures is not known. In this research work, therefore, only this influence will be investigated. In order to separate the effects and influences, all test runs are carried out with constant velocities. The tests are performed for the two velocity levels at $v_{1}=4.2 \mathrm{~m} / \mathrm{s}$ $(10001 / \mathrm{min})$ and $v_{2}=10 \mathrm{~m} / \mathrm{s}(23871 / \mathrm{min})$. To avoid the risk of thermal damage (especially at $\theta=120^{\circ} \mathrm{C}$ ), there is no circumferential velocity tested above $v_{2}=10 \mathrm{~m} / \mathrm{s}$. The running distance is set at $9450 \mathrm{~km}$ for both velocities. This results in a test run duration of $t_{1}=625 \mathrm{~h}$ for $v_{1}=4.2 \mathrm{~m} / \mathrm{s}$ and a test run duration $t_{2}=262.5 \mathrm{~h}$ for $v_{2}=10 \mathrm{~m} / \mathrm{s}$. All test runs are carried out without overpressure due to a vented test chamber and with a period duration $t_{\mathrm{z}}=2 \mathrm{~h}$.

\section{RESULTS AND DISCUSSION}

The following section describes the evaluation of the test rig design, the measured wear width after test run and the discussion of the experimental results.

\subsection{Evaluation of the test ring design}

In order to evaluate the function of the additional test chamber, a preliminary test run is carried out before the start of the actual test series. The reachable minimum and maximum oil sump temperatures as well as the temperature gradients are tested. For this purpose, the test chamber is equipped with a sealing system and filled with oil up to the center of the shaft. The sealing system used is equivalent to the main test series described in chapter 2.3. The shaft diameter is $\varnothing 80 \mathrm{~mm}$. The test is performed at a constant circumferential speed of $v_{2}=10 \mathrm{~m} / \mathrm{s} \quad\left(n_{2}=23871 / \mathrm{min}\right)$. The temperature profile is specified as an alternation 
between $5^{\circ} \mathrm{C}$ and $120^{\circ} \mathrm{C}$ with a period duration $t_{\mathrm{z}}=2 \mathrm{~h}(1 \mathrm{~h}$ at lower temperature, $1 \mathrm{~h}$ at higher temperature). Fig. 8 shows the measured temperature profile and the temperature gradient.

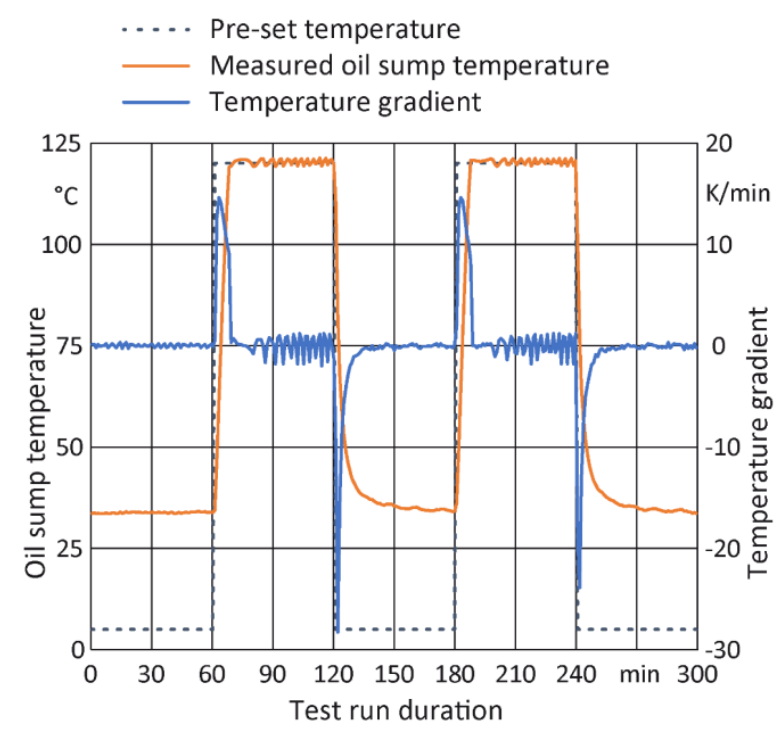

Fig. 8. Preliminary test run with sealing system $\varnothing 80 \mathrm{~mm}$ and circumferential speed of $v_{2}=10 \mathrm{~m} / \mathrm{s}$ $\left(n_{2}=23871 / \mathrm{min}\right)$ : Temperature and temperature gradient over time

The pre-set temperature of $5{ }^{\circ} \mathrm{C}$ can of course not be reached with a cooling water temperature of approx. $18{ }^{\circ} \mathrm{C}$. However, in this way it should be checked, which minimum temperature can be reached while incorporating the frictional power of the running sealing system. A state of equilibrium of approx. $35{ }^{\circ} \mathrm{C}$ is reached for the given $10 \mathrm{~m} / \mathrm{s}$ of circumferential velocity. The maximum temperature of $120^{\circ} \mathrm{C}$ can be reached without any problems. The temperature is measured at an interval of $60 \mathrm{~s}$. The specified temperature gradient is therefore calculated approximately with

$$
\frac{\Delta \theta}{\Delta t}=\frac{\theta_{n+1}-\theta_{n}}{1 \min }
$$

The heating time from $35^{\circ} \mathrm{C}$ to $120^{\circ} \mathrm{C}$ is approx. $8 \mathrm{~min}$. As soon as cooling water is supplied, temperature gradients of over $30 \mathrm{~K} / \mathrm{min}$ are achieved for a short time. Due to the decreasing temperature difference between cooling water and test chamber, the temperature gradient quickly decreases again. Approx. $10 \mathrm{~min}$ are required for cooling to $40^{\circ} \mathrm{C}$.

The aim of the new development was to enable test runs with dynamic temperature changes at high frequencies. This aim is achieved. Within the tested $2 \mathrm{~h}$ cycle, the cumulative heating and cooling time is only $18 \mathrm{~min}$. The temperature specifications can be achieved with sufficient accuracy.

\subsection{Experimental results}

In the first step, the wear width of the reference tests with constant temperatures are evaluated. Fig. 9 shows the results for $v_{1}=4.2 \mathrm{~m} / \mathrm{s}$ on the left and the results for $v_{2}=10 \mathrm{~m} / \mathrm{s}$ in the middle.

For statistical reasons, at least two test runs are always carried out for each load collective. If a large scatter between the wear widths of these two radial lip seals occurs, further test runs must be carried out for statistical validation. The first two test results of test run $\mathrm{a}_{2}$ show a great difference in wear formation. The maximum wear width of $a_{2.1}$ is still below the minimum wear width of $a_{2.2}$ (see Fig. 9, right). This test is therefore repeated. After the repetition (test run $\mathrm{a}_{2.3}$ and $\mathrm{a}_{2.4}$ ), there is only a small scatter of the resulting wear with.

Fig. 10 and Fig. 11 show the effects of dynamic temperature changes on the wear width. The tests with alternating temperatures are each shown between the corresponding reference test runs.

\subsection{Discussion}

The reference test runs in Fig. 9 show at both velocity levels a significant decrease in wear with increasing oil sump temperatures. The sealing edges with a large maximum wear width show also a strong asymmetric wear which means there is a greater difference between the minimum and maximum value. At the higher circumferential velocity $v_{2}=10 \mathrm{~m} / \mathrm{s}$ the wear width is lower at the same oil sump temperatures. This could lead to the conclusion that operating conditions with sealing gap temperatures above $120^{\circ} \mathrm{C}$ are the least harmful. However, it should be noted that the risk of thermal damage increases significantly from this point. The risk of chemical damage also increases with increasing temperature.

The decreasing wear can be explained by several effects. Firstly, the radial load $F_{\mathrm{R}}$ of a radial lip seal depends on the temperature $F_{R}(\theta)$. It decreases with increasing temperature. The radial load is measured $F_{\mathrm{R}}\left(\theta=40^{\circ} \mathrm{C}\right) \approx 30 \mathrm{~N}$ and $F_{\mathrm{R}}\left(\theta=120^{\circ} \mathrm{C}\right) \approx 24 \mathrm{~N}$. A reduced radial load means less contact pressure of the sealing edge on the shaft and thus potentially less wear. On the other hand, the temperature has a major effect on the kinematic viscosity of the oil used. The kinematic viscosity decreases exponential with increasing temperature [21]. A change in viscosity goes hand in hand with other effects regarding the interface physics of the shaft surface and sealing edge surface in particular. 

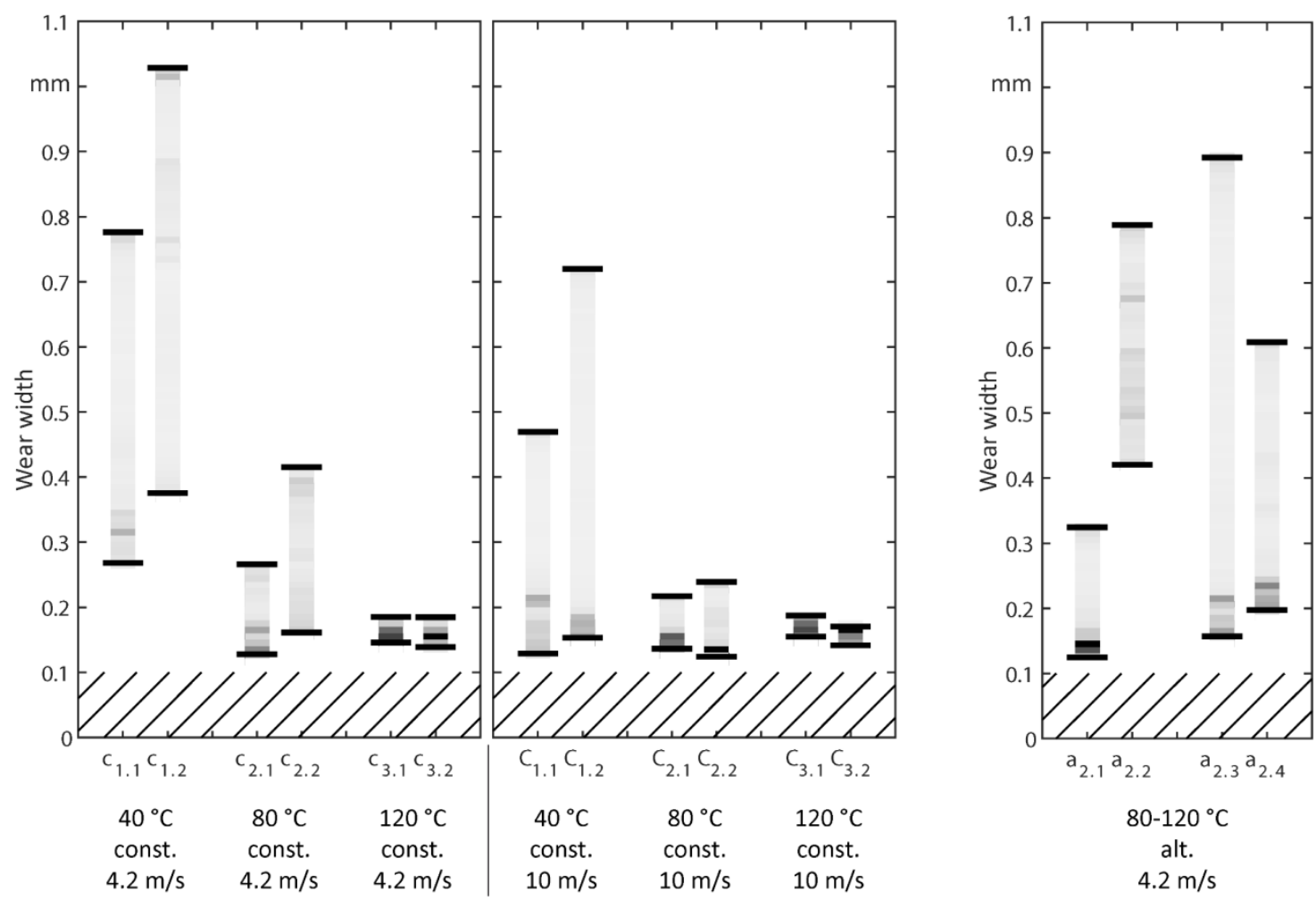

Fig. 9. Wear width of the sealing edges: Reference test runs with constant temperatures (left: $v_{1}=4.2 \mathrm{~m} / \mathrm{s}, \mathrm{middle}$ : $v_{2}=10 \mathrm{~m} / \mathrm{s}$ ) and repetition of test run a2 (right). Operating conditions, see Table 2. Values below $0.1 \mathrm{~mm}$ indicate only an initial rounding of the sealing edge, which is already present in the new condition. Up to $0.1 \mathrm{~mm}$ only minimal initial wear occur
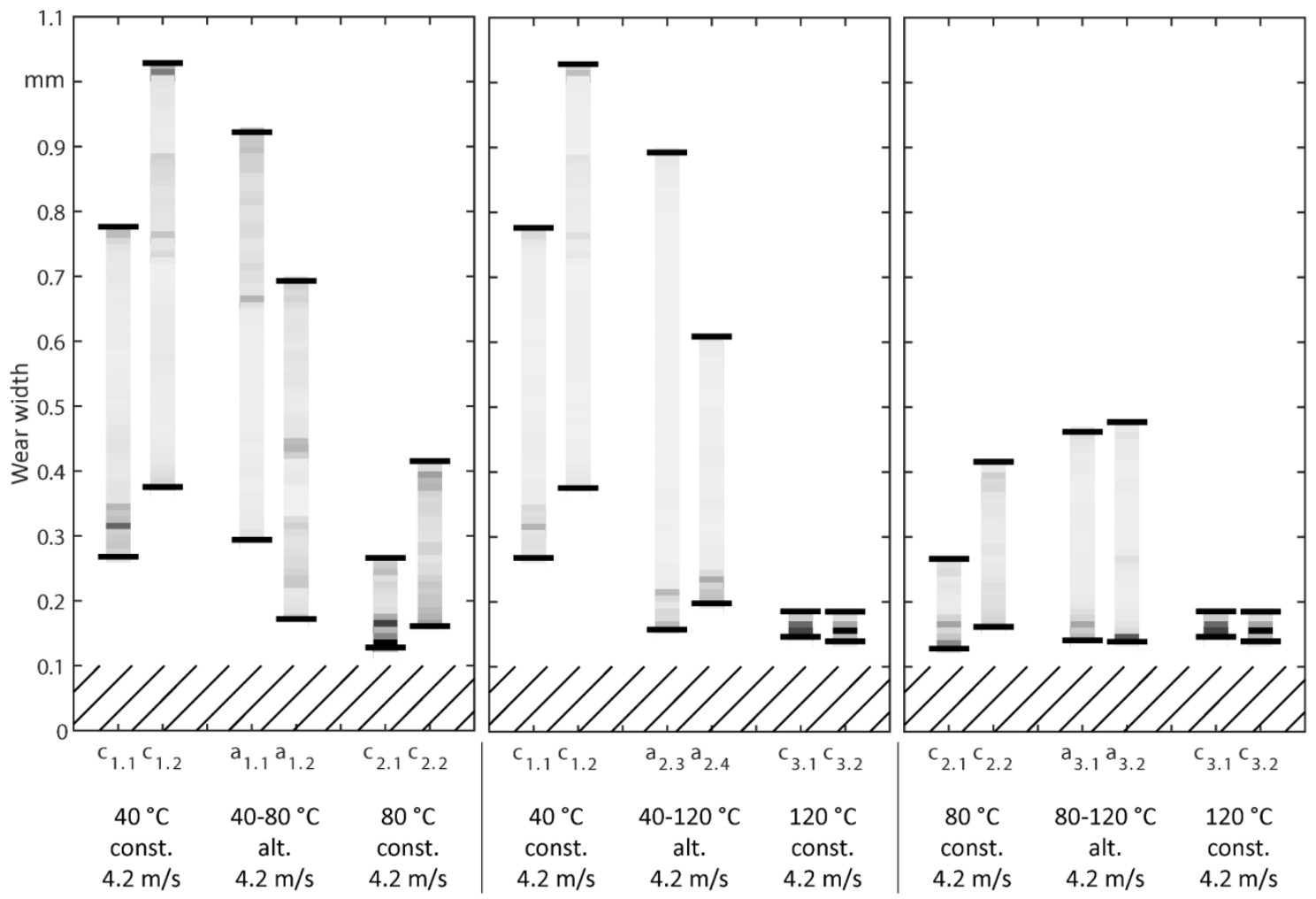

Fig. 10. Wear width of the sealing edges: Test runs with alternating temperature at circumferential velocity $v_{1}=4.2 \mathrm{~m} / \mathrm{s}$. Operating conditions, see Table 2 . Values below $0.1 \mathrm{~mm}$ indicate only an initial rounding of the sealing edge, which is already present in the new condition. Up to $0.1 \mathrm{~mm}$ only minimal initial wear occur 


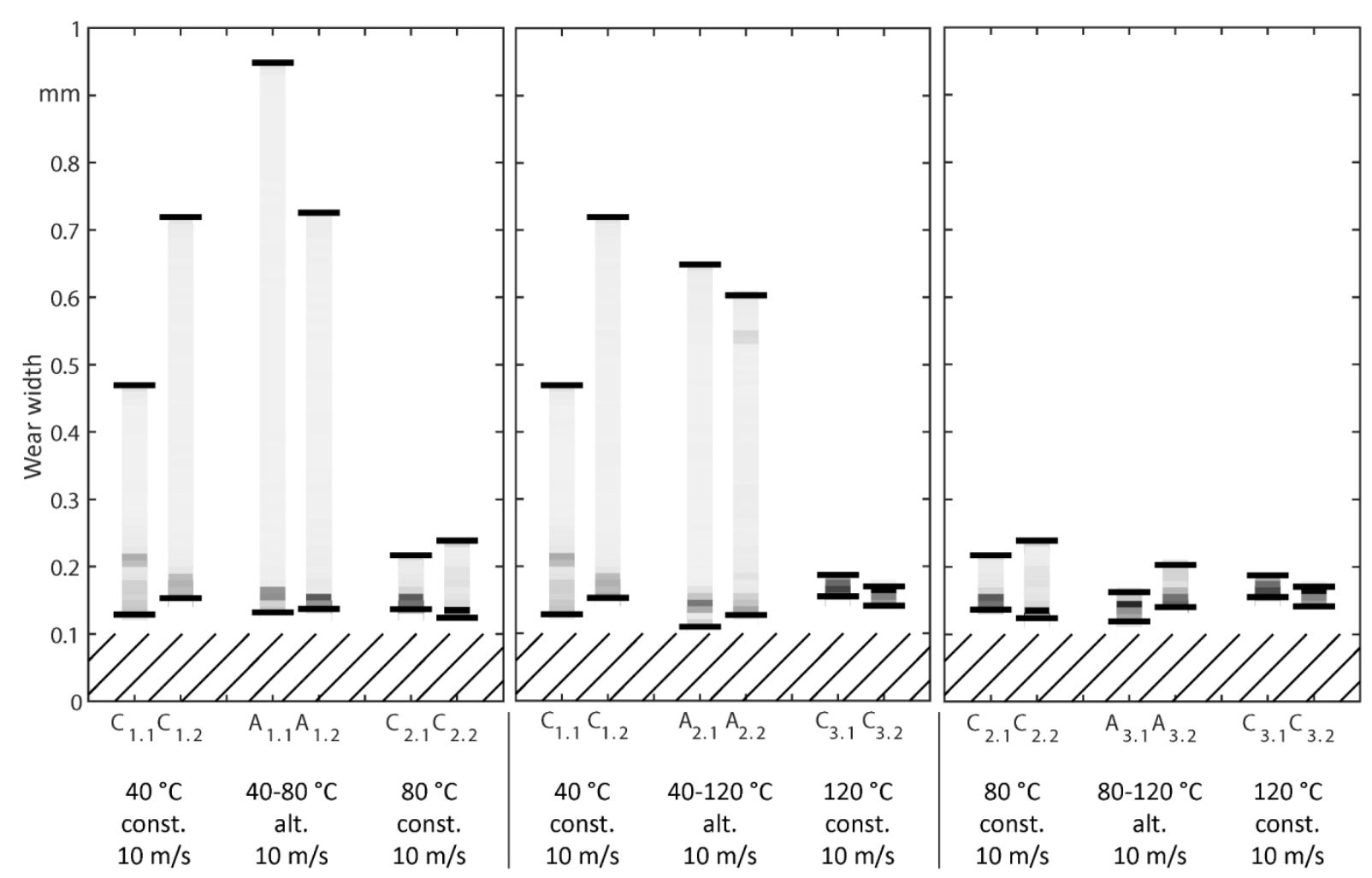

Fig. 11. Wear width of the sealing edges: Test runs with alternating temperature at circumferential velocity $v_{2}=10 \mathrm{~m} / \mathrm{s}$. Operating conditions, see Table 2 . Values below $0.1 \mathrm{~mm}$ indicate only an initial rounding of the sealing edge, which is already present in the new condition. Up to $0.1 \mathrm{~mm}$ only minimal initial wear occur

So, they also have an influence on the lubrication condition and therefore on the wear behavior.

The test results with alternating temperatures in Fig. 10 show, a varying temperature places a higher tribological load on the sealing system. The level of the wear width in tests with dynamic temperature changes is comparable to the results with constant exposure to the lower temperature level, despite proportional exposure to higher oil sump temperatures. Which means that the lower temperature level, despite a temporally identical share in the load collective, apparently causes a larger share in the present wear. Test run $c_{2}$ with constant $\theta=80^{\circ} \mathrm{C}$ oil sump temperature and test run $c_{3}$ with constant $\theta=120^{\circ} \mathrm{C}$ oil sump temperature show both lower wear widths than test run $a_{3}$ with an alternating oil sump temperature between $\theta=80^{\circ} \mathrm{C}$ and $\theta=120^{\circ} \mathrm{C}$.

Fig. 11 shows the test results of the test runs with a circumferential speed of $v_{2}=10 \mathrm{~m} / \mathrm{s}$ in the same form as Fig. 10. The evaluation of the tests shows the same overall picture as the tests with $v_{1}=4.2 \mathrm{~m} / \mathrm{s}$. The maximum of the wear width at low temperature is in general about $0.1 \mathrm{~mm}$ narrower than in the tests at low speed. With increasing temperature, the wear width also decreases here. The difference between collectives with changing temperatures to collectives with constant temperatures is even more striking in tests with $v_{2}=10 \mathrm{~m} / \mathrm{s}$. Again, the level of wear width in tests with dynamic temperature changes is at least comparable to the results with constant exposure to the lower temperature level. Test run $C_{1}$ with constant $\theta=40^{\circ} \mathrm{C}$ oil sump temperature and test run $\mathrm{C}_{2}$ with constant $\theta=80^{\circ} \mathrm{C}$ oil sump temperature shows both lower wear width than test run $A_{1}$ with an alternating oil sump temperature between $\theta=40^{\circ} \mathrm{C}$ and $\theta=80^{\circ} \mathrm{C}$.

The effects of dynamic temperature changes are particularly evident when considering the experiments with $80^{\circ} \mathrm{C}$ constant and alternating between 40 and $120^{\circ} \mathrm{C}$. Test run $\mathrm{C}_{2}$ with constant $\theta_{2}=80^{\circ} \mathrm{C}$ oil sump temperature show wear widths of $0.2 \ldots 0.25 \mathrm{~mm}$. Test run $\mathrm{A}_{2}$ with an alternating oil sump temperature between $\theta_{1}=40^{\circ} \mathrm{C}$ and $\theta_{3}=120^{\circ} \mathrm{C}$ has the same average temperature as $C_{2}$, but shows wear widths of up to $0.65 \mathrm{~mm}$.

All sealing edges with large wear widths also show strong asymmetric wear. This means that there are areas on the sealing ring with a narrow wear width and areas where the wear width is very wide. For further clarification, Fig. 12 shows the evaluation of the wear width of test $a_{1}$ and $A_{1}$ in the polar representation. It becomes clear what can already be seen in the bar chart representation: In test run $a_{1}$, the different wear widths are evenly distributed. 


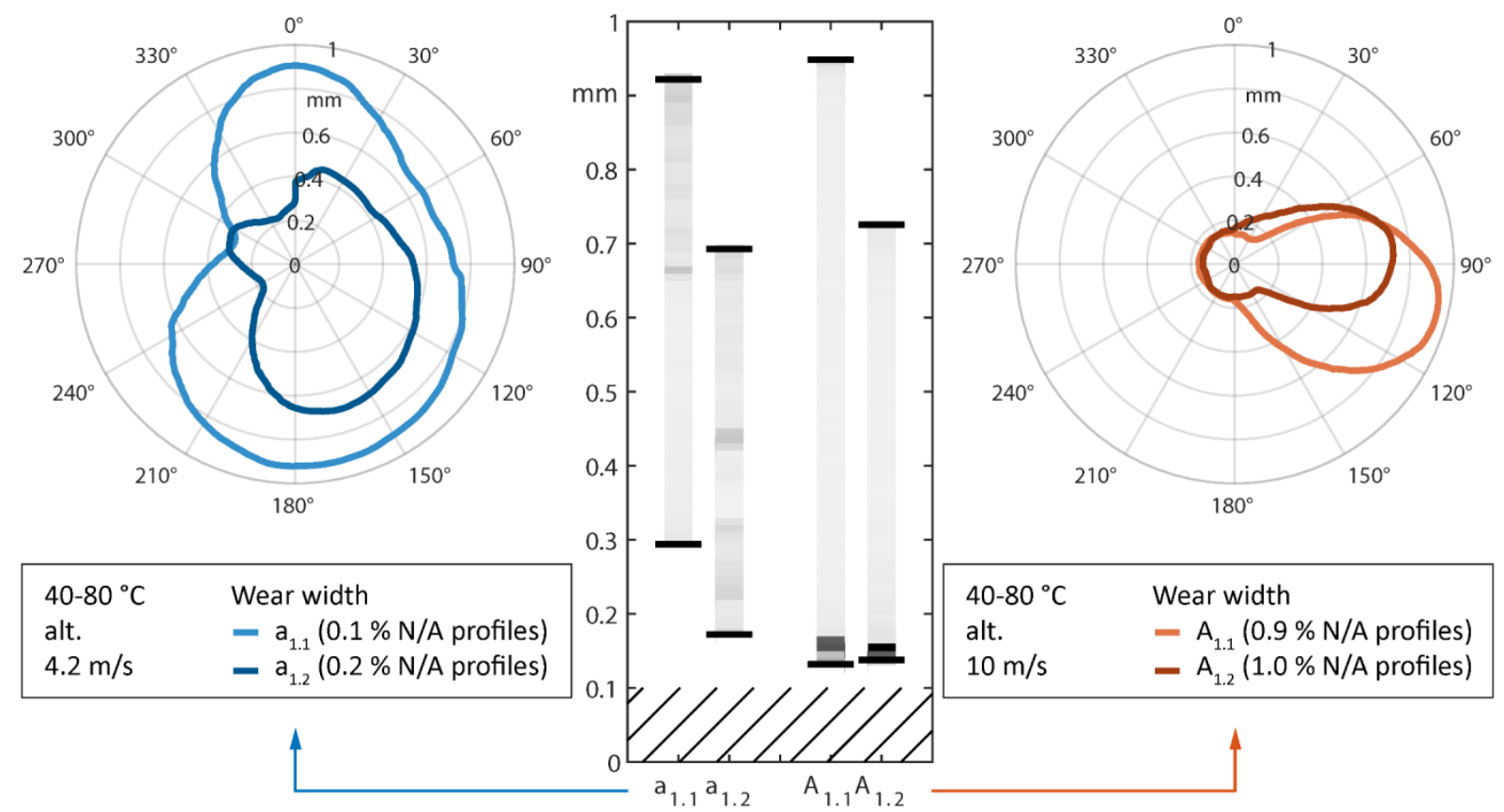

Fig. 12. Asymmetric wear width of the sealing edges after test run a1 and A1: Test runs with alternating temperature $\vartheta=40 \ldots 80^{\circ} \mathrm{C}$ at circumferential velocity v1 $=4.2 \mathrm{~m} / \mathrm{s}$ (left) and $\mathrm{v} 2=10 \mathrm{~m} / \mathrm{s}$ (right). Comparison between bar plot and polar plot. Values below $0.1 \mathrm{~mm}$ indicate only an initial rounding of the sealing edge, which is already present in the new condition. Up to $0.1 \mathrm{~mm}$ only minimal initial wear occur

There are a similar number of areas around the circumference of the sealing ring with low, medium and high wear. The curves in the polar diagram are rather uniform. In contrast, the distribution of test $A_{1}$ is very uneven. Over a very large angular range, only small wear widths are measured, while the maximum wear width is reached in a section of approx. $90^{\circ}$. The different distributions of the asymmetric wear can be observed not only in the two tests shown in Fig. 12. All tests at a velocity of $v_{1}=4.2 \mathrm{~m} / \mathrm{s}$ show a uniform distribution of the wear width. In contrast, all tests with a velocity of $v_{2}=10 \mathrm{~m} / \mathrm{s}$ show narrow wear widths in most areas of the sealing edge, and a large wear width only in small angular sections.

The formation of asymmetric wear does not depend on the test rig design, nor is it due to manufacturing errors in seal production or due to eccentricity deviations of the components. All sealing systems were comprehensively measured and checked before the test. The formation of asymmetrical wear is reproducible on different test rigs with different sealing rings depending only on the operating conditions. Four additional test chambers are used for the tests, which are combined with different test modules. Comparable results are achieved at all times. The asymmetry of the wear at the sealing edges therefore has a tribological reason. The exact cause of asymmetric wear is still unclear. Different fluid flow conditions or an inhomogeneous material composition are conceivable, which in conjunction with unfavorable operating conditions promote asymmetrical wear.

To ensure all results are valid, all sealing edges are analyzed comprehensively after the test runs. A visual analysis is only necessary to exclude other types of damage. A summary of common methods for failure analysis after test runs in addition to the wear width measurement can be found at [23]. A more detail view regarding all possible cases of failure can be found at [3]. In this case, apart from abrasive wear, no further failure is found. The sealing edges show no thermal or chemical damage. During the running time of the tests, no leakage occurred. Even the seals with wear width $>1 \mathrm{~mm}$ remained leak tight. The sealing quality of radial lip seals strongly depends on the operating conditions [24]. At this point, the question remains open as starting from which wear width leakage actually occurs.

\section{Summary and Conclusion}

A new additional test chamber was designed and used for the investigation of the influence of high temperature gradients on the wear behavior of radial lip seals. A test series was carried out, using different constant temperature levels and load collectives with fast changing temperature levels. The obtained results show, that rapid changing oil 
sump temperatures, increase the wear rate on the seals, when compared to different constant temperature levels. In addition, all radial lip seals studied showed highly asymmetric wear after being subjected to rapid temperature cycling. Premature seal failures in retarder applications can thus be explained by the high temperature gradients that result in increased wear rates. This behavior must therefore be considered when designing the service life of such applications.

Alternating temperatures mean a constant change of tribological conditions in the sealing contact. The change in boundary conditions causes the components to adapt to the new condition each time when the systems keeps the new condition after the change for some time. Wear occurs therefore with each adaptation (running-in to the new operating conditions). The overall wear rate is therefore higher than in continuous operation. This applies equally to changes in temperature, such as changes in velocity. Of course, this behavior only occurs under operating conditions that do not cause any thermal damage to the elastomer material. Thermal damage to the radial lip seal would cause a completely different behavior. The observed wear behavior is fully consistent with the findings of Eipper [10]. The investigation of different changing velocities also shows significantly increased wear under transient operating conditions. Further investigations will follow to enable optimization potentials or a better description of the tribological function.

\section{NOTE}

The abstract of this paper is published at the $10^{\text {th }}$ International Conference on Tribology BALKANTRIB '20 organised in Belgrade, on May 2022, 2021.

\section{REFERENCES}

[1] Deutsches Institut für Normung e.V., RadialWellendichtringe, 1996. [in German]

[2] Deutsches Institut für Normung e.V., RadialWellendichtringe für Kraftfahrzeuge - Begriffe; Maßbuchstaben; zulässige Abweichungen; Radialkraft, 1984. [in German]

[3] F. Bauer, Federvorgespannte - Elastomer Radial - Wellendichtungen. Springer Fachmedien, Wiesbaden, 2021. [in German] https://doi.org/10.1007/978-3-658-32922-8

[4] F. Bauer, Tribologie. Springer Fachmedien Wiesbaden, Wiesbaden, 2021. [in German] https://doi.org/10.1007/978-3-658-32920-4

[5] Deutsches Institut für Normung e.V., RadialWellendichtringe für Kraftfahrzeuge Funktionsprüfung; Prüfstand und Prüfbedingungen, 1984. [in German]

[6] Deutsches Institut für Normung e.V., RadialWellendichtringe für Kraftfahrzeuge Funktionsprüfung; Leckage-Beurteilung, 1984. [in German]

[7] A. Hüttinger, J. Hermes, M. Wöppermann, E. Prem, Neues Prüfverfahren für dynamische Dichtungen von Getriebemotoren, in: Friedrich Berger, Sandra Kiefer (Eds.), Jahrb. Dichtungstechnik 2016. ISGATEC GmbH, Mannheim, 2015: pp.482-494. [in German]

[8] Freudenberg Sealing Technologies, Dynamic oil compatibility tests for Freudenberg radial shaft seals to release the usage in FLENDER-gear units applications (Table T 7300), 2020.

[9] Sew-Eurodrive GmbH \& Co KG, Prüfvorschrift $\begin{array}{lllll}97 & 118 & 04 & 15 & 63190052.04 \\ \text { Statische und }\end{array}$ dynamische Prüfungen von Radialwellendichtringen (RWDR), 2020.

[10] A. Eipper, Einfluss transienter Betriebsbedingungen auf den RWDR im System Radial-Wellendichtung (Ph.D. Thesis). Institute of Machine Components, University of Stuttgart, Stuttgart, 2018. [in German] http://dx.doi.org/10.18419/opus-9986

[11] A. Eipper, F. Bauer, W. Haas, Damaging process of radial lip seals considering variable temperature and runtime, in: Proc. $13^{\text {th }}$ EDF/Pprime Work., 2014.

[12] T. Engelke, Einfluss der Elastomer-Schmierstoff - Kombination auf das Betriebsverhalten von Radialwellendichtringen, Universität Hannover, 2011.

[13] L. Schöneweiß, Design of a Test Rig for Temperature Tests on Radial Shaft Seals, (Unpublished student thesis). Institute of Machine Components, University of Stuttgart, Stuttgart, 2020. [in German]

[14] J. Grün, S. Feldmeth, F. Bauer, Wear on radial lip seals: a numerical study of the influence on the sealing mechanism, Wear, 476, 2021: 203674. https://doi.org/10.1016/j.wear.2021.203674

[15] F. Guo, X. Jia, W. Longke, R.F. Salant, Y. Wang, The effect of wear on the performance of a rotary lip seal. Journal of Tribology, 136, 2014: 1-8. https://doi.org/10.1115/1.4027623

[16] M. Baumann, F. Bauer, Moderne visuelle Untersuchungsmethoden für die 
Verschleißanalyse am Beispiel RadialWellendichtring, in: Proc. 20th Int. Seal. Conf., Fachverband Fluidtechnik im VDMA e.V, Frankfurt am Main, 2018: pp. 93-104. [in German]

[17] M. Baumann, Abdichtung drallbehafteter Dichtungsgegenlaufflächen - Messung, Analyse, Bewertung und Grenzen (Ph.D. Thesis). Institute of Machine Components, University of Stuttgart, Stuttgart, 2017. [in German] http://dx.doi.org/10.18419/opus-9061

[18] M. Schulz, M. Hagmayer, M. Baumann, F. Bauer, Analysis of Fluid Flow in the Sealing Gap of Radial Shaft Seals and Elastic Deformation of the Sealing Surface. Journal of Tribology, 143 (12), 2021: 1-19. https://doi.org/10.1115/1.4050139

[19] M. Baumann, F. Bauer, W. Haas, Ra, Rz und Rmax von Dichtungsgegenlaufflächen -- der Weisheit letzter Schluss?, in: Friedrich Berger, Sandra Kiefer (Eds.), Jahrb. Dichtungstechnik 2016. ISGATEC GmbH, Mannheim, 2015, pp. 295-309. [in German]

[20] Technical Manual, Freudenberg Sealing
Technologies $\mathrm{GmbH}$ \& Co. KG, Weinheim Germany, 2015.

[21] Forschungsvereinigung Antriebstechnik e.V., Referenzölkatalog - Datensammlung. FVA, Frankfurt am Main, 2007. [in German]

[22] M. Jaunich, Tieftemperaturverhalten von Elastomeren im Dichtungseinsatz (Ph.D. Thesis). BAM Bundesanstalt für Materialforschung und - prüfung, Technische Universität Berlin, Berlin, 2011. [in German]

[23] L. Merkle, M. Baumann, F. Bauer, Best Practice for Individual Test Design Based on Given Application Parameters and Failure Analysis on Radial Shaft Seals, in: 61. Tribol. 2020 Reibung, Schmierung Und Verschleiß Forsch. Und Prakt. Anwendungen. GfT Gesellschaft für Tribologie e.V., Jülich, 2020.

[24] M. Remppis, Untersuchungen zum Förderverhalten von Dichtsystemen mit Radial-Wellendichtringen aus Elastomer (Ph.D. Thesis). Institute of Machine Components, University of Stuttgart, Stuttgart, 2016. [in German] http://dx.doi.org/10.18419/opus-8975 